\title{
Molecular Variability Within and Among Verticillium dahliae Vegetative Compatibility Groups Determined by Fluorescent Amplified Fragment Length Polymorphism and Polymerase Chain Reaction Markers
}

\author{
Melania Collado-Romero, Jesús Mercado-Blanco, Concepción Olivares-García, \\ Antonio Valverde-Corredor, and Rafael M. Jiménez-Díaz
}

\begin{abstract}
First, second, and fourth authors: Instituto de Agricultura Sostenible (IAS), Consejo Superior de Investigaciones Científicas (CSIC), Apartado 4084, 14080 Córdoba, Spain; and third and fifth authors: IAS-CSIC and Escuela Técnica Superior de Ingenieros Agrónomos y Montes, Universidad de Córdoba, Apartado 3048, 14080 Córdoba, Spain.
\end{abstract}

Accepted for publication 16 January 2006.

ABSTRACT

\begin{abstract}
Collado-Romero, M., Mercado-Blanco, J., Olivares-García, C., ValverdeCorredor, A., and Jiménez-Díaz, R. M. 2006. Molecular variability within and among Verticillium dahliae vegetative compatibility groups determined by fluorescent amplified fragment length polymorphism and polymerase chain reaction markers. Phytopathology 96:485-495.

A degree of genetic diversity may exist among Verticillium dahliae isolates within vegetative compatibility groups (VCGs) that bears phytopathological significance and is worth investigating using molecular tools of a higher resolution than VCG characterization. The molecular variability within and among $V$. dahliae VCGs was studied using 53 artichoke isolates from eastern-central Spain, 96 isolates from cotton, 7 from cotton soil, and 45 from olive trees in countries of the Mediterranean Basin. Isolates were selected to represent the widest available diversity in cotton- and olive-defoliating (D) and -nondefoliating (ND) pathotypes, as well as for VCG. The VCG of 96 cotton and olive isolates was determined in this present study. Molecular variability among $V$. dahliae isolates was assessed by fluorescent amplified fragment length polymorphism (AFLP) analysis and by polymerase chain reaction (PCR) assays for DNA fragments associated with the D (462 bp) and ND (824 bp) pathotypes, as well as a 334-bp amplicon associated with D pathotype isolates but also present in some VCG2B isolates. Isolates from cotton were in VCG1A, VCG1B, VCG2A, VCG2B, and VCG4B and
\end{abstract}

those from olive trees were in VCG1A, VCG2A, and VCG4B. Artichoke isolates included representatives of VCG1A, VCG2A, VCG2B (including a newly identified VCG2Ba), and VCG4B. AFLP data were used to generate matrixes of genetic distance among isolates for cluster analysis using the neighbor-joining method and for analysis of molecular variance. Results demonstrated that $V$. dahliae isolates within a VCG subgroup are molecularly similar, to the extent that clustering of isolates correlated with VCG subgroups regardless of the host source and geographic origin. VCGs differed in molecular variability, with the variability being highest in VCG2B and VCG2A. For some AFLP/VCG subgroup clusterings, $V$. dahliae isolates from artichoke grouped in subclusters clearly distinct from those comprising isolates from cotton and olive trees. In addition, VCG2B isolates from artichoke formed two distinct clusters that correlated with PCR markers of 334 bp $\left(\mathrm{VCG} 2 \mathrm{~B}^{334}\right)$ or 824 bp $\left(\mathrm{VCG} 2 \mathrm{~B}^{824}\right)$. Artichoke isolates in the $\mathrm{VCG} 2 \mathrm{~B}^{334} / 2 \beta^{334}$ cluster were molecularly similar to isolates of VCG1A. The molecular difference found among artichoke isolates in VCG2B correlates with virulence of isolates to artichoke and cotton cultivars demonstrated in a previous study.

Additional keywords: Cynara cardunculus, Gossypium hirsutum, Olea europaea.
Verticillium wilt, caused by the soilborne fungus Verticillium dahliae Kleb., affects a large number of crops and woody plants and is among the most important and difficult to manage plant diseases worldwide (45). For example, Verticillium wilt is one of the major constraints for production of artichoke (Cynara cardunculus L. var. scolymus), cotton (Gossypium hirsutum L.), and olive (Olea europaea L.) in many areas of the world $(3,6,9,14,21$, $27,37,50,61)$. Studies during the last decade have demonstrated that genetic diversity within the populations of this pathogen is higher than previously thought, and that limited understanding of the nature of such diversity has hampered the progress of understanding disease development and the efficacy of its management $(4,30,48)$.

Genetic diversity in $V$. dahliae has been studied mainly by means of vegetative compatibility grouping and, to a lesser extent, analyses of the fungal DNA. Vegetative compatibility refers to the genetically controlled ability of individual fungal strains to under-

Corresponding author: R. M. Jiménez-Díaz; E-mail address: ag1jidir@uco.es

DOI: 10.1094/PHYTO-96-0485

(c) 2006 The American Phytopathological Society go hyphal anastomosis and form stable heterokaryons. Isolates of a fungal species that are vegetatively compatible are placed in the same vegetative compatibility group (VCG) $(30,36)$. Because $V$. dahliae is a haploid, strictly asexually reproducing fungus, hyphal fusion is a prerequisite to genetic exchange among different isolates of the pathogen (45). Therefore, $V$. dahliae isolates from different VCGs are thought to be genetically isolated populations which may vary in a number of ecological, physiological, and virulence traits $(30,48)$. The use of complementing nitratenonutilizing (nit) mutants has led to identifying four main VCGs (VCG1, VCG2, VCG3, and VCG4) among V. dahliae isolates from diverse host sources and geographic origins worldwide $(7,11,18,21,28,32,33)$. Recently, VCG6 was identified among V. dahliae isolates infecting pepper in California (8). Based on the frequency and vigor of complementation, VCG1, VCG2, and VCG4 were further divided into two subgroups, designated A and $\mathrm{B}$, and a set of isolates and nit mutants testers were described for the four main VCGs and VCG subgroups (7,28-30,32,48,53). Results from the few studies based on V. dahliae VCGs associated with specific crops and geographic areas indicate that limited VCG diversity generally occurs and that a correlation may exist between virulence and the VCG of the isolates $(8,26,29,32,33,53)$. 
Conversely, $V$. dahliae isolates in the same VCG from different hosts may or may not differ in host range, suggesting that this pathogenicity trait is an isolate's characteristic probably determined by selection pressure established by cropping practices $(9,23,59)$. In a recent study $(26)$, VCG2B, comprising $V$. dahliae isolates infecting artichoke in eastern-central Spain, was found to be genetically heterogeneous. This was indicated by the VCG2B isolates being differentiated into two subgroups, designated VCG2Br if the isolates complemented with international reference testers and $\mathrm{VG} 2 \mathrm{Ba}$ if the complementation occurred with $\mathrm{VCG} 2 \mathrm{Br}$ isolates but not with the reference testers (26). Also, VCG2Ba and VCG2Br isolates showed diversity in the polymerase chain reaction (PCR) markers of 334 and 824 bp that previously were associated with the cotton- and olive-defoliating (D) or -nondefoliating (ND) $V$. dahliae pathotypes, respectively $(15,38,39)$, although more recent work has shown that the 334-bp amplicon is not only with the D pathotype (26). Moreover, such genetic heterogeneity correlated with virulence to artichoke and cotton (26). Therefore, a degree of genetic diversity may exist among $V$. dahliae isolates within a VCG from the same or different crops and geographic areas. This bears phytopathological significance and is worth investigating using molecular analyses that provide a higher resolution for characterization of strains than VCG characterization.

Molecular studies of genetic diversity in V. dahliae populations yielded contradictory results but, overall, indicated a lack of clear molecular distinction between $V$. dahliae VCGs. Restriction fragment length polymorphism analyses indicated that molecular subgroupings of isolates were associated with host sources and geographic origins $(42,43)$ as well as VCG $(19,25,43)$. Similarly, random amplified polymorphic DNA (RAPD) analyses grouped $V$. dahliae isolates from diverse host sources and geographic origins according to VCGs (60). In contrast, in a different study, a similar correlation of RAPD markers was not found with isolates from diverse host sources in the same geographic area (9). Furthermore, there were differences in banding patterns when isolates from different hosts in the same VCG were compared by RAPD analyses (8). Also, RAPD analyses of $V$. dahliae isolates from cotton in the same (Spain) or different countries (Israel and Spain) grouped isolates according to the D or ND nature of isolates, and this grouping correlated with the VCG of the D isolates (i.e., VCG1A) but not with the ND isolates (which belong to VCG2A, VCG2B, and VCG4B) $(33,44)$. Likewise, PCR amplicons specific for $V$. dahliae showed sequence variability and there was not complete correlation between the sequences of these amplicons and VCG of the isolates $(10,15)$. Lack of a clear molecular distinction among $V$. dahliae VCGs suggests that some gene flow might occur among them. This poses a risk that new virulence or pathogenicity phenotypes may develop in the pathogen population. Therefore, there is a need to better characterize molecular variability among and within $V$. dahliae VCGs. This could be achieved by using more sensitive molecular techniques, such as amplified fragment length polymorphisms (AFLPs) (58), which already have been used successfully for the study of genetic variability and population structure in Verticillium spp. from different hosts (22), V. dahliae from Brassica spp. (16,22), and V. alboatrum from hops (Humulus lupulus L.) (46).

In this present research, we aim to determine the nature of molecular variability within and among $V$. dahliae VCGs using AFLP analysis and selected isolates from quite different hosts (i.e., artichoke, cotton, and olive trees) with either a narrow or wide geographic origin. The specific objectives of this study were to (i) determine whether or not $V$. dahliae VCGs are genetically distinct and (ii) assess the molecular variability that might occur within individual $V$. dahliae VCGs. To that aim, we used AFLP analysis and PCR markers which previously have been associated with the D and ND pathotypes and purposely selected a large set of isolates differing in host and geographic origins.

\section{MATERIALS AND METHODS}

V. dahliae isolates and culture conditions. In all, 210 monoconidial $V$. dahliae isolates were used in this study, which represented a wide diversity in geographic origin, VCG, and D and ND virulence phenotypes on cotton and olive, and PCR amplification of markers that were associated with the D and ND phenotypes of $V$. dahliae. Of the 210 isolates, 53 isolates originated from artichoke, 103 isolates were from cotton and cotton soil, and 45 isolates were from olive trees. All artichoke isolates were from the Comunidad Valenciana in eastern-central Spain. Cotton and olive isolates originated from countries in the Mediterranean Basin (Cyprus, Greece, Israel, Italy, Spain, and Syria), except for seven cotton isolates from California (five isolates) and China (two isolates) (Table 1). Eight additional isolates were included in the study as representative of VCGs not represented among artichoke, cotton, and olive isolates. These isolates originated from shrubs or woody hosts (six isolates) and pepper (Capsicum annum L.) (two isolates) (8). Also, one isolate each of $V$. dahliae var. longisporum from cauliflower (Brassica oleraceae L. var. botrytis) in California, $V$. albo-atrum from hop, and $V$. nigrescens from potato (Solanum tuberosum L.) in the United Kingdom were included in the study for comparisons. Isolates were stored on plum lactose yeast extract agar (PLYA) (54) covered with liquid paraffin at $4^{\circ} \mathrm{C}$ in the dark (5). Isolates are deposited in the culture collection of the Departamento de Protección de Cultivos, Instituto de Agricultura Sostenible, Consejo Superior de Investigaciones Científicas, Córdoba, Spain. Active cultures of isolates were obtained on water agar amended with chlorotetracycline $(0.3 \mathrm{~g} / \mathrm{liter})$ and subsequent subculturing on potato dextrose agar (PDA) (250 g of unpeeled potato, $20 \mathrm{~g}$ of agar, and $20 \mathrm{~g}$ of glucose per liter of distilled water) or, alternatively, PLYA.

Generation and characterization of nit mutants and determination of vegetative compatibility. All artichoke isolates and $50 \%$ of the cotton isolates were previously characterized to VCG $(26,32,33)$. The 53 artichoke $V$. dahliae isolates used in this present work were purposely selected as representatives of the VCG diversity at the Comunidad Valenciana Region of easterncentral Spain (26). In all, 35 isolates (66\%) belonged to VCG2B (including the subgroups VCG2Ba and VCG2Br), 12 isolates $(22.6 \%)$ to VCG2A, 3 isolates $(5.7 \%)$ to VCG4B, 1 isolate $(1.9 \%)$ to VCG1A, and 2 isolates $(3.8 \%)$ are heterokaryon selfincompatible (HSI) (Table 1).

In this present study, 51 isolates of $V$. dahliae from cotton (50 isolates) and cotton soil (1 isolate) and 45 isolates from olive trees were characterized to VCG by complementation tests of nit mutants using international reference testers (Table 1). nit mutants were generated on water agar chlorate (WAC) and were tested further on Czapek-Dox agar (CDA) (Difco Laboratories, Detroit, MI) according to Korolev and Katan (31) at $25^{\circ} \mathrm{C}$ and a 12-h photoperiod of fluorescent and near-UV light at $36 \mu \mathrm{Em}^{-2} \mathrm{~s}^{-1}$ for up to 4 weeks. Phenotype of nit mutants was determined on CDA amended with sodium nitrite $(0.5 \mathrm{~g} / \mathrm{liter})$ or hypoxanthine (0.2 g/liter) (17).

The nit 1 and NitM mutants from each isolate were used to test for heterokaryon self-compatibility as well as for complementation with nit mutants of the international Ohio Agricultural Research and Development Center (OARDC, The Ohio State University, Woodster, $\mathrm{OH}$ ) reference strains of $V$. dahliae VCGs (VCG1A, VCG3, and VCG4A) and Israeli nit testers (VCG1A, VCG2A, VCG2B, and VCG4B) (32) in all possible combinations. A NitM mutant of artichoke isolate V396I, a tester for VCG2Ba (26), also was used. In all, the following testers were used: VCG1A, T9M NitM, and cot200 nit1 from cotton; VCG2A, Ep8 NitM, and Ep5 nit1 from eggplant; VCG2B, cot11 NitM, and cot 254 nit 1 from cotton; VCG3, 70-21 NitM from pepper; VCG4A, $131 \mathrm{M}$ NitM, and 171 nit 1 from potato; and VCG4B, Pt15M NitM, and Pt9G nit 1 from potato. Pairings were scored for 
prototrophic growth after 2 and 4 weeks of incubation at the same conditions as above. Complementation was indicated by the formation of a dense, aerial growth or black microsclerotia where mycelia from an unknown and a tester strain had met and formed a prototrophic heterokaryon. In such a case, the unknown mutant was considered vegetatively compatible with the tester strain and was assigned to the VCG of the tester strain.

Extraction of fungal DNA. DNA was extracted from mycelia of 6- to 7-day-old cultures of Verticillium isolates in Czapek-Dox broth (44), or by scrapping off the surface of colonies developed on a cellophane disk placed on PLYA (54). Harvested mycelia were freeze dried, and $20 \mathrm{mg}$ were ground to a fine powder in 2-ml tubes with glass beads in a Fast Prep Instrument (BIO 101, Carlsbad, CA). DNA was extracted from ground mycelia using the DNeasy Plant Kit (Qiagen, Hilden, Germany). DNA purity and concentration were determined spectrophotometrically using a Biophotometer (Eppendorf AG, Hamburg, Germany) and by agarose gel electrophoresis according to standard procedures. DNA solutions were stored at $-20^{\circ} \mathrm{C}$ until used. A modification of the HotSHOT method described by Truett et al. (55) was used for rapid and small-scale DNA extraction. Briefly, a small amount of mycelia, scraped off PLYA colonies with the tip of a sterile pipette, was disrupted in $20 \mu \mathrm{l}$ of $25 \mathrm{mM} \mathrm{NaOH}, 0.2$ disodium EDTA, pH 12, solution in 0.2-ml PCR tubes. These solutions were incubated for $1 \mathrm{~h}$ at $95^{\circ} \mathrm{C}$ and $5 \mathrm{~min}$ at $4^{\circ} \mathrm{C}$ in a thermocycler and $20 \mu \mathrm{l}$ of $40 \mathrm{mM}$ Tris- $\mathrm{HCl}, \mathrm{pH} 5$, was added afterward. Of this lysate, 5 to $8 \mu \mathrm{l}$ was used directly for PCR assays.

Specific PCR assays. All $V$. dahliae isolates in the study were characterized by PCR assays using several primer pairs. The use of primer pair DB19/DB22 (10) yields $V$. dahliae-specific polymorphic DNA bands of 539 or $523 \mathrm{bp}$ (38). The use of primer pairs INTD2f/INTD2 $r$ and INTND2f/INTND2r produce PCR markers of 462 or $824 \mathrm{bp}$ that previously were associated with the $\mathrm{D}$ and ND pathotypes of $V$. dahliae, respectively (38-40). Conversely, primer pair DB19/espdef01 amplifies a 334-bp marker which is present in $\mathrm{D}$ isolates and also in some ND isolates of VCG1B and VCG2B (15). Primer pairs INTD2f/INTD2r and INTND2f/INTND2r were used jointly in duplex PCR assays. Amplification conditions were $(25 \mu \mathrm{l}$ total volume) $20 \mathrm{ng}$ of fungal DNA, $100 \mathrm{nM}$ each primer, $200 \mathrm{nM}$ each dNTP, $2 \mathrm{mM}$ $\mathrm{MgCl}_{2}, 2.5 \mu \mathrm{l}$ of $10 \times$ reaction buffer, and 0.75 units of EcoTaq polymerase (Ecogen S.R.L., Barcelona, Spain). PCR conditions were $94^{\circ} \mathrm{C}$ for $4 \mathrm{~min} ; 30$ cycles of $94^{\circ} \mathrm{C}$ for $1 \mathrm{~min}, 64^{\circ} \mathrm{C}$ for $1 \mathrm{~min}$, and $72^{\circ} \mathrm{C}$ for $1 \mathrm{~min}$; and a final step of $6 \mathrm{~min}$ at $72^{\circ} \mathrm{C}$. Primer pair DB19/DB22 was used alone as well as jointly with primer espdef01 as described previously (38), but the annealing temperature for the multiplex use of the three primers was raised to $60^{\circ} \mathrm{C}$

AFLP assays. AFLP assays were performed using a fluorescent procedure modified from the radioactive method of Vos et al. (58). AFLP reactions were done using the AFLP Small Plant Genomes Kit (Applied Biosystems, Foster City, CA) according to the manufacturer's instructions. Genomic DNA (50 ng) was digested with $M s e I$ and EcoRI endonucleases (New England Biolabs, Beverly, MA), and the restricted DNA fragments were ligated to $M s e \mathrm{I}$ and EcoRI adaptors (provided in the kit) using T4 DNA ligase (USB Corporation, Cleveland, OH). Thereafter, $5.5 \mu \mathrm{l}$ of this reaction was diluted to $5 \%$ in $\mathrm{TE}_{0.1}$ buffer $(10 \mathrm{mM}$ Tris-Cl, $\mathrm{pH} 7.5,0.1 \mathrm{mM}$ EDTA) and $4 \mu \mathrm{l}$ of the dilution was used for preselective amplification $(20 \mu \mathrm{l})$ using $0.5 \mu \mathrm{l}$ of preselective primers MseI-C and EcoRI-0 (2 $\mu \mathrm{M}$ each) and $15 \mu \mathrm{l}$ of the AFLP Core Mix included in the kit. Preselective and fluorescently labeled (NED, JOE, and FAM dyes) selective primers were supplied by Applied Biosystems. Conditions for preselective PCR were $72^{\circ} \mathrm{C}$ for $2 \mathrm{~min} ; 20$ cycles of $94^{\circ} \mathrm{C}$ for $20 \mathrm{~s}, 56^{\circ} \mathrm{C}$ for $30 \mathrm{~s}$, and $72^{\circ} \mathrm{C}$ for $2 \mathrm{~min}$; and a final step of $60^{\circ} \mathrm{C}$ for $30 \mathrm{~min}$; $10 \mu \mathrm{l}$ of the reaction product was diluted in $95 \mu \mathrm{l}$ of $\mathrm{TE}_{0.1}$. In all cases, $5.5-\mu \mathrm{l}$ aliquots of the restriction-ligation products and $10 \mu \mathrm{l}$ of the preselective products were tested by electrophoresis in $1.5 \%$ (wt/vol) agarose gels stained with ethidium bromide.

For selective PCR amplifications, four EcoRI-XX-Dye/MseI-C combinations were used in independent reactions: EcoRI-ATNED, EcoRI-AG-JOE, EcoRI-GC-FAM, and EcoRI-GA-FAM. PCR selective reactions consisted of (final volume, $20 \mu \mathrm{l}) 3 \mu \mathrm{l}$ of diluted preselective reaction, $1 \mu \mathrm{l}$ of each selective primer (EcoRIXX-Dye, $1 \mu \mathrm{M}$ and MseI-C, $5 \mu \mathrm{M}$ ), and $15 \mu \mathrm{l}$ of the Core Mix provided with the kit. Reaction conditions for the selective amplification were $2 \mathrm{~min}$ at $94^{\circ} \mathrm{C}$ followed by 10 cycles of $94^{\circ} \mathrm{C}$ for $20 \mathrm{~s}, 66$ to $57^{\circ} \mathrm{C}$ for $30 \mathrm{~s}$, and $72^{\circ} \mathrm{C}$ for $2 \mathrm{~min}$ (in which the annealing temperature decreased by $1^{\circ} \mathrm{C}$ in each cycle); 20 cycles of $94^{\circ} \mathrm{C}$ for $20 \mathrm{~s}, 56^{\circ} \mathrm{C}$ for $30 \mathrm{~s}$, and $72^{\circ} \mathrm{C}$ for $2 \mathrm{~min}$; and a final step of $60^{\circ} \mathrm{C}$ for $30 \mathrm{~min}$. All preselective and selective reactions were done in a GeneAmp PCR System 9600 (Perkin Elmer/ Applied Biosystems, Foster City, CA). Products of selective amplifications were separated by capillary electrophoresis in an automatic DNA sequencer (ABI Prism 3100 Genetic Analyzer; Applied Biosystems). The size of products was determined using GeneScan-500 [ROX] (Applied Biosystems) as internal size standard ( 35 to $500 \mathrm{bp}$ ). Four AFLP profiles, one for each of the selective primer combinations used, ranging from 50 to $490 \mathrm{bp}$, were established for each of isolates in the study using the GeneScan analysis software (version 2.0; Applied Biosystems). Artifacts in the AFLP profiles were avoided by using replicates of V. dahliae isolates V318I and V517II for the DNA extraction step, isolate V698I for the restriction-ligation reaction step, and isolate V800I for the preselective amplification step. Moreover, some of the selective and preselective amplifications were repeated for arbitrarily selected isolates (V4I, V143I, V145I, V217I, V361I, V362I, V404II, V138I, V403II, and V302I), and AFLP patterns that represented diversity among isolates were highly consistent (i.e., fluorescent peaks were well resolved and unambiguous).

Scoring of AFLP fragments and data analysis. AFLP profiles were assessed individually. Only unambiguous peaks were scored for presence or absence $(1=$ presence or $0=$ absence $)$ using Genotyper software (version 2.5; Applied Biosystems). All DNA fragments within the range of 50 to $490 \mathrm{bp}$ first were selected using the 'unmark overlapping peaks' option and AFLP profiles were rescaled using the 'normalize scale' option. Unambiguous, consistent peaks which scaled higher than 100 fluorescence units then were selected and those inconsistent were deleted manually. A binary character matrix was developed by combining all data and used for subsequent analysis. The TREECON software (57) was used to develop two phenetic trees. Genetic distances were computed using either the Nei and Li (41) or simple matching (52) methods. In the Nei and Li method, the genetic distance, GDxy, between two isolates ( $x$ and $y$ ) is computed as GD $x y=1-$ $(2 \mathrm{~N} x y /[\mathrm{N} x+\mathrm{N} y])$, where $\mathrm{N} x y$ is the number of DNA fragments shared by isolates $x$ and $y$, and $\mathrm{N} x$ and $\mathrm{N} y$ are the number of DNA fragments in isolates $x$ and $y$, respectively. In the simple matching method (52), the genetic distance, GDxy, between two isolates is computed as GD $x y=1-\left(\left[\mathrm{N}^{+} x y+\mathrm{N}^{-} x y\right] / \mathrm{Nt}\right)$, in which $\mathrm{N}^{+} x y$ and $\mathrm{N}^{-} x y$ are the number of positive and negative matches, respectively, of DNA fragments between isolates $x$ and $y$, and $\mathrm{Nt}$ is the total number of DNA fragments. The genetic distance matrixes were used to generate two phenograms using the neighbor-joining (NJ) method (49). A bootstrap analysis of 1,000 permutations was used to test reliability of branches in the trees. AFLP data also were subjected to analysis of molecular variance (AMOVA) (20) to identify and analyze molecular variability among isolates using the Arlequin software (version 2000; Genetic and Biometry Laboratory, University of Geneva, Switzerland). This procedure converts a phenotypic distance matrix into an equivalent analysis of variance, and allows estimation of variance components for AFLP haplotypes by partitioning the variance among and within samples. Variance components from the 


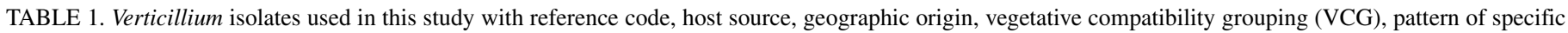
polymerase chain reaction (PCR) amplicons, clustering by amplified fragment length polymorphic (AFLP) analysis, and biological pathotyping on cotton

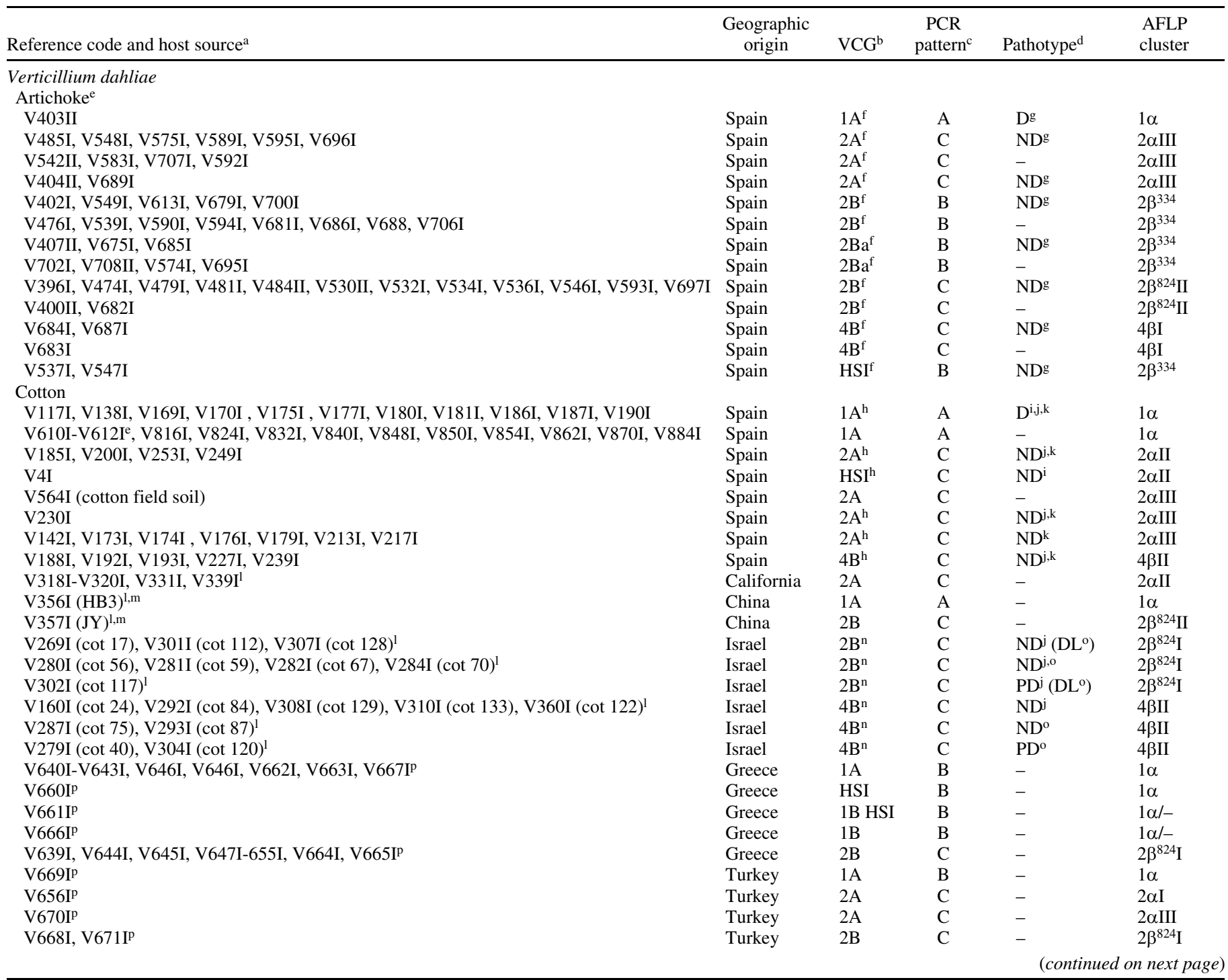

${ }^{a}$ Reference code in parenthesis refers to that used by other authors in previous works. The code on the last isolate of a group listed refers to all isolates in the group.

b $2 \mathrm{Ba}=$ VCG2B isolates from artichoke in the Comunidad Valenciana Region that did not complement with VCG2B international reference testers, but showed positive complementation with nitrate-nonutilizing (nit) mutants of VCG2B isolates from artichoke in that Region (26); * $=$ nit mutants could not be produced.

c PCR markers pattern: A = 334 bp (+), 824 bp (-), 462 bp (+); B = 334 bp (+), 824 bp (-), 462 bp (-); and C = 334 bp (-), 824 bp (+), 462 bp (-); - = none of these markers were amplified.

${ }^{\mathrm{d}} \mathrm{D}=$ cotton defoliating, $\mathrm{ND}=$ cotton nondefoliating, $\mathrm{PD}=$ partially defoliating according to Korolev et al. (32), DL = defoliating-like according to Korolev et al. (33), $-=$ not determined.

e J. Armengol, Universidad Politécnica de Valencia, Valencia, Spain.

${ }^{\mathrm{f}}$ VCG assessment of isolates made by Jiménez-Díaz et al. (26); HSI = heterokaryon self-incompatible.

g Determined by artificial inoculation on cotton by Jiménez-Díaz et al. (26).

${ }^{\mathrm{h}}$ VCG assessment of isolates made by Korolev et al. (33).

i Determined by artificial inoculation on cotton by Bejarano-Alcázar et al.(5).

j Determined by artificial inoculation on cotton by Korolev et al. (33).

${ }^{\mathrm{k}}$ Determined by artificial inoculation on cotton by Pérez-Artés et al. (44).

${ }^{1}$ T. Katan, The Volcani Center, Bet Dagan, Israel.

mPérez-Artés et al. (44).

${ }^{\mathrm{n}}$ VCG assessment of isolates made by Korolev et al. (32).

${ }^{o}$ Determined by artificial inoculation on cotton by Korolev et al. (32).

p E. Paplomatas, Agricultural University of Athens, Athens, Greece.

q A. Zazzerini, Università degli Studi di Perugia, Perugia, Italy.

${ }^{\mathrm{r}}$ F. Nigro, Università degli Studi di Bari, Bari, Italy.

s M. Al-Ahmad, Plant Protection Service, Damascus, Syria.

${ }^{t}$ Collins et al. $(15,16)$.

u D. Barbara, Warwick HRI, England, UK.

${ }^{v}$ Bhat et al. (8).

${ }^{\mathrm{w}}$ VCG assessment of isolates made by Bhat et al. (8).

${ }^{x}$ Chen (11).

y VCG assessment of isolates made by N. Korolev, J. Katan, R. M. Jiménez-Díaz, and T. Katan (unpublished data). 


\begin{tabular}{|c|c|c|c|c|c|}
\hline Reference code and host source ${ }^{a}$ & $\begin{array}{l}\text { Geographic } \\
\text { origin }\end{array}$ & $\mathrm{VCG}^{\mathrm{b}}$ & $\begin{array}{c}\text { PCR } \\
\text { pattern }^{c}\end{array}$ & Pathotype $^{\mathrm{d}}$ & $\begin{array}{l}\text { AFLP } \\
\text { cluster }\end{array}$ \\
\hline \multicolumn{6}{|l|}{ Soil (cotton field) } \\
\hline V523I (scot2), V524I (scot3), V525I (scot5), V527I (scot7), V528I (scot9), V529I (scot 12) & Israel & $4 \mathrm{~B}^{\mathrm{n}}$ & $\mathrm{C}$ & - & $4 \beta \mathrm{II}$ \\
\hline \multicolumn{6}{|l|}{ Olive } \\
\hline V135I, V136I, V137II, V150I, V151I, V153I & Spain & $1 \mathrm{~A}$ & A & $\mathrm{D}^{\mathrm{k}}$ & $1 \alpha$ \\
\hline V314I, V932I, V937I & Spain & $1 \mathrm{~A}$ & A & - & $1 \alpha$ \\
\hline V149I & Spain & $2 \mathrm{~A}$ & $\mathrm{C}$ & $\mathrm{ND}^{\mathrm{k}}$ & $2 \alpha I I$ \\
\hline V143I-V145I, V147I, V148I, V152I & Spain & $2 \mathrm{~A}$ & $\mathrm{C}$ & $\mathrm{ND}^{\mathrm{k}}$ & $2 \alpha I I I$ \\
\hline V315I, V800I & Spain & $2 \mathrm{~A}$ & $\mathrm{C}$ & - & $2 \alpha \mathrm{III}$ \\
\hline V392I, V789I, V792I, V796I, V798I, V803I, V805I & Spain & 4B & $\mathrm{C}$ & - & $4 \beta \mathrm{II}$ \\
\hline V384I (I3) $)^{\mathrm{m}, \mathrm{q}}, \mathrm{V} 712 \mathrm{II}, \mathrm{V} 716 \mathrm{I}, \mathrm{V} 720 \mathrm{II}^{\mathrm{r}}$ & Italy & $2 \mathrm{~A}$ & $\mathrm{C}$ & - & $2 \alpha I$ \\
\hline V713II ${ }^{\mathrm{r}}$ & Italy & $2 \mathrm{~A}$ & $\mathrm{C}$ & - & $2 \alpha I I$ \\
\hline V714II, V717I, V718I ${ }^{\mathrm{r}}$ & Italy & $2 \mathrm{~A}$ & $\mathrm{C}$ & - & $2 \alpha I I I$ \\
\hline V361I-V366I & Syria & $2 \mathrm{~A}$ & $\mathrm{C}$ & - & $2 \alpha \mathrm{I}$ \\
\hline V657I, V811I, V812Ip & Cyprus & $2 \mathrm{~A}$ & $\mathrm{C}$ & - & $2 \alpha \mathrm{I}$ \\
\hline V658I & Cyprus & HSI & $\mathrm{C}$ & - & $2 \beta^{824} \mathrm{II}$ \\
\hline V672I, V674IP & Greece & $4 \mathrm{~B}$ & $\mathrm{C}$ & - & $4 \beta I I$ \\
\hline \multicolumn{6}{|l|}{ Pepper } \\
\hline V561I (VdCa147a) $)^{\mathrm{t}}, \mathrm{V} 560 \mathrm{I}(\mathrm{VdCa} 83 \mathrm{a})^{\mathrm{u}, \mathrm{v}}$ & California & $6^{\mathrm{w}}$ & $\mathrm{C}$ & - & 6 \\
\hline \multicolumn{6}{|l|}{ Yellowwood (Cladrastis lutea) } \\
\hline V517II $(9-6)^{\mathrm{l}, \mathrm{u}, \mathrm{x}}$ & Illinois & $1 \mathrm{~B}^{\mathrm{y}}$ & $\mathrm{B}$ & - & $1 \beta$ \\
\hline \multicolumn{6}{|l|}{ Japanese maple (Acer palmatum) } \\
\hline V518II (1990-1) $)^{\mathrm{l}, \mathrm{u}, \mathrm{x}}$ & Illinois & $1 \mathrm{~B}^{\mathrm{y}}$ & $\mathrm{B}$ & - & $1 \beta$ \\
\hline \multicolumn{6}{|l|}{ Velvet leaf (Lavatera arborea) } \\
\hline V606I (VL2C) $)^{1}$ & Minnesota & $1 \mathrm{~B}^{\mathrm{y}}$ & $\mathrm{B}$ & - & $1 \beta$ \\
\hline \multicolumn{6}{|l|}{ Green ash (Fraxinus pennsylvanica) } \\
\hline V607I (RO4), V608I (A9) & Minnesota & $1 \mathrm{~B}^{\mathrm{y}}$ & $\mathrm{B}$ & - & $1 \beta$ \\
\hline \multicolumn{6}{|l|}{ Green mountain sugar maple (Acer saccharum) } \\
\hline V609I (M1) $)^{1}$ & Minnesota & $1 \mathrm{~B}^{\mathrm{y}}$ & $\mathrm{B}$ & - & $1 \beta$ \\
\hline \multicolumn{6}{|l|}{$V$. dahlie var. longisporum } \\
\hline \multicolumn{6}{|l|}{ Cauliflower } \\
\hline V559I $(90-10)^{\mathrm{u}}$ & California & $*$ & - & - & - \\
\hline \multicolumn{6}{|l|}{ V. albo-atrum } \\
\hline \multicolumn{6}{|l|}{ Hops } \\
\hline V48I (V-48 898, mild) ${ }^{\mathrm{u}}$ & England & - & - & - & - \\
\hline \multicolumn{6}{|l|}{$V$. nigrescens } \\
\hline \multicolumn{6}{|l|}{ Potato } \\
\hline V51I (V-51 1880) & England & - & - & - & - \\
\hline
\end{tabular}

analysis can be used to calculate the $\Phi$ statistic $\left(\Phi_{\mathrm{ST}}\right)$ that summarizes the degree of differentiation between population divisions and is analogous to Wright's $F$ statistic (20). AMOVA was performed to test population structure both among and within VCGs. Comparisons were done by computing $\Phi_{\mathrm{ST}}$ between pairs of populations. The level of significance for $\Phi_{\mathrm{ST}}$ values was computed by 3,000 permutations and established at $P<0.05$.

\section{RESULTS}

Molecular characterization of isolates by specific PCR assay. All V. dahliae isolates used in this present study yielded the species-specific 539 or 523 bp polymorphic DNA bands in PCR assays using the DB19/DB22 primer pair, as observed by Mercado-Blanco et al. (38). In contrast, neither $V$. albo-atrum nor $V$. nigrescens isolates yielded those markers in similar assays (Table 1). In addition, V. dahliae isolates (except one of $V$. dahliae var. longisporum isolate) produced one of three patterns of PCR products (namely, A, B, and C) when assayed with primer pairs DB19/espdef01 (amplification product of $334 \mathrm{bp}$ ), INTD2f/INTD2r (462-bp amplicon), and INTND2f/INTND2r (824-bp amplicon) (Table 1). The amplification of the cotton and olive D (462 bp) and ND (824 bp) associated markers, as well as of the 334-bp fragment, hereby was used as a preliminary indication of molecular diversity among isolates. Those PCR patterns were found in isolates irrespective of their host source (Table 1), but varied among VCGs. For example, $V$. dahliae isolates from Greece and Turkey assigned to VCG1A showed the B pattern, whereas VCG1A isolates from Spain and China showed the A pattern for these markers (Table 1). In addition, VCG2B isolates from artichoke in eastern-central Spain exhibited the B or C pattern (Table 1).
Vegetative compatibility of $\boldsymbol{V}$. dahliae isolates. All 50 $V$. dahliae isolates from cotton, 1 isolate from cotton soil, and 45 isolates from olive produced nit 1 mutants, but only $21.5 \%$ of the isolates produced NitM mutants. The isolate from cauliflower did not produce chlorate-resistant sectors on WAC. Positive complementation reactions of those mutants with nit mutants of the international OARDC reference strains and Israeli tester strains allowed assignment of the tested $V$. dahliae isolates to VCG. Two cotton isolates from Greece, as well as one olive isolate from $\mathrm{Cy}$ prus, were HSI. Therefore, VCG1A, VCG1B, VCG2A, VCG2B, and VCG4B were represented in the $201 \mathrm{~V}$. dahliae isolates in this study, and five isolates were HSI (Table 1).

Of the 45 olive isolates, $9(20 \%)$ isolates were assigned to VCG1A, $26(57.7 \%)$ to VCG 2A, 9 (20\%) to VCG4B, and isolate V658I from Cyprus was HSI. The isolates in VCG2A originated from Cyprus, Italy, Spain, and Syria. All the olive isolates in VCG1A were from Spain, but isolates of VCG4B were from Greece and Spain (Table 1).

Similarly, of the 50 isolates from cotton and 1 isolate from cotton soil characterized to VCG in this study, 23 (45.1\%) isolates were assigned to VCG1A, $2(3.9 \%)$ to VCG1B, $8(15.7 \%)$ to VCG2A, 17 (33.3\%) to VCG2B, and isolate V660I from Greece was HSI. Overall, the $103 \mathrm{~V}$. dahliae isolates from cotton (96 isolates) and cotton soil (7 isolates) were the most diverse in geographic origin and were grouped in VCG1A, VCG1B, VCG2A, VCG2B, and VCG4B. VCG1A was the most prevalent VCG among cotton isolates with 34 isolates (33\% of the isolates), followed by VCG2B with $25(24.3 \%)$ isolates, VCG2A and VCG4B with $20(19.4 \%)$ isolates each, and VCG1B with 2 $(1.9 \%)$ isolates (Table 1). Isolates V660I from Greece and V4I from Spain were HSI. VCG1A included isolates from China, 
Greece, Spain, and Turkey; VCG2B comprised isolates from China, Greece, Israel, and Turkey; VCG2A was represented by isolates from California, Spain, and Turkey; and VCG4B comprised isolates from Israel and Spain. The two isolates in VCG1B were from Greece, of which one (V661I) was HSI. Finally, the six $V$. dahliae isolates from shrubs and woody hosts were of VCG1B (Table 1).

A noteworthy correlation between the VCG of isolates and the PCR pattern of amplification was found in some cases (Table 1). For example, VCG1A isolates from artichoke, cotton, and olive obtained from Spain or China all showed the pattern A characterized by the amplification of the 334- and 462-bp DNA fragments. However, VCG1A isolates from cotton in Greece and Turkey did not amplify the 462-bp marker associated with D isolates but produced the 334-bp DNA fragment only (i.e., the B pattern of PCR amplification). This B pattern also was produced by isolates of VCG1B from diverse host sources and geographic origins (Table 1). Isolates assigned to VCG2A, VCG4B, and VCG6 amplified the 824-bp marker associated with ND isolates only (i.e., pattern $\mathrm{C}$ ), regardless of host source and geographic origin. Isolates of VCG2B which were recovered from artichoke and cotton showed the highest diversity in the pattern of PCR markers. Thus, whereas all VCG2B cotton isolates produced the $\mathrm{C}$ pattern, artichoke isolates of VCG2Br exhibited either pattern B (designated $\mathrm{VCG} 2 \mathrm{Br}^{334}$ ) or $\mathrm{C}$ (designated as $\mathrm{VCG} 2 \mathrm{Br}^{824}$ ). However, all artichoke isolates of $\mathrm{VCG} 2 \mathrm{Ba}$ showed the $\mathrm{B}$ pattern (designated VCG2Ba ${ }^{334}$ ). For isolates from other hosts, VCG2B isolates that produced the 824-bp PCR marker were denoted VCG2B ${ }^{824}$ and VCG2B isolates that yielded the 334-bp fragment were denoted VCG2B ${ }^{334}$.

AFLP analysis. In all, 489 unambiguous and easily discernible AFLP fragments were obtained from the 210 Verticillium isolates, including 130 DNA fragments with EcoRI-AG/MseI-C, 90 with EcoRI-GC/MseI-C, 142 with EcoRI-GA/MseI-C, and 127 with EcoRI-AT/MseI-C. All DNA fragments were polymorphic when AFLP fingerprints of isolates of $V$. albo-atrum, $V$. dahliae var. longisporum, and $V$. nigrescens were included in the analysis. However, only 280 AFLP fragments were polymorphic when $V$. albo-atrum and V. nigrescens were excluded, and just 213 fragments were polymorphic if the isolate of $V$. dahliae var. longisporum also was disregarded. Replicates of isolates V800I, V689I, V318I, and V517II of $V$. dahliae (designated $a$ and $b$ in Fig. 1), grouped together in the AFLP clusters corresponding to their VCG (described below).

The NJ analysis of genetic distance computed by the simple matching method and the Nei and Li method in general gave similar results, and only those using the simple matching method are shown (Fig. 1). V. dahliae isolates were grouped in two main clusters that correlated with the presence of the 334- or 824-bp PCR markers. These main clusters, designated as the 334- and 824-bp clusters, were supported by a bootstrap value of $100 \%$. The 334-bp cluster contained isolates assigned to VCG1A, VCG1B, and VCG2B ${ }^{334}$, and the 824-bp cluster included isolates of VCG2B ${ }^{824}$, VCG6, VCG4B, and VCG2A (Fig. 1; Table 1). There were eight clusters within the two main clusters and they correlated with the VCG of the isolates (i.e., an AFLP cluster grouped isolates assigned to a same VCG subgroup) (Fig. 1). Therefore, AFLP clusters were designated according to the VCG of isolates that they grouped (i.e., AFLP clusters: $1 \alpha, 1 \beta, 2 \alpha$, $2 \beta^{334}, 2 \beta^{824}, 6,4 \beta \mathrm{I}$, and $4 \beta \mathrm{II}$ ) (Table 1; Fig. 1). All clusters were supported by bootstrap values higher than $95 \%$, except for the $2 \alpha$ and $4 \beta$ II clusters. As expected, isolates of $V$. albo-atrum, $V$. dahliae var. longisporum, and V. nigrescens were clearly discriminated from the $V$. dahliae clusters. AMOVA analysis of the whole set of AFLP data showed that $83.38 \%$ of total variation was due to differences among the identified AFLP clusters (Table 2), and only $7.36 \%$ of the total variation was due to differences within them.
In the 334-bp cluster, cotton isolates V661I and V666I of VCG1B from Greece were placed out of the AFLP clusters $1 \alpha$ and $1 \beta$ (Fig. 1), although differentiation between $1 \alpha$ and $1 \beta$ clusters lacked significant bootstrap support (46\%). Nevertheless, AMOVA of AFLP data supported isolates in $1 \alpha$ and $1 \beta$ AFLP clusters as significantly $(P<0.001)$ different $V$. dahliae populations (Table 2). Interestingly, amplification of the 462-bp V. dahliae marker associated with the D pathotype from VCG1A isolates differentiated isolates from Spain from those from Greece and Turkey, which were similar. AMOVA of the AFLP data for VCG1A isolates indicated that there was a significant $(P<0.001)$ difference between cotton and olive isolates from Spain and cotton isolates from Greece and Turkey, and between cotton isolates from Spain and those from Greece (data not shown).

$V$. dahliae isolates from artichoke in eastern-central Spain, yielding the $\mathrm{B}$ pattern of PCR amplifications and assigned to VCG2 $\mathrm{Ba}^{334}$ or VCG2Br ${ }^{334}$, were grouped in AFLP cluster $2 \beta^{334}$. These isolates were separated from AFLP cluster $2 \beta^{824}$ that comprised artichoke isolates of VCG2 $\mathrm{Br}^{824}$ and all other VCG2B isolates yielding only the 824-bp marker associated with the ND pathotype (i.e., the C pattern) (Table 1). The AFLP cluster $2 \beta^{334}$ also contained artichoke HSI isolates V537I and V547I. No further subgrouping of isolates within this latter cluster occurred that could be associated with differences in VCG of isolates (Table 2). Isolates in the AFLP cluster $2 \beta^{824}$ were clearly differentiated from pepper $V$. dahliae isolates V561I and V560I of VCG6 by bootstrap values of $95 \%$ (Fig. 1). Isolates of the $2 \beta^{824}$ cluster were grouped in two subclusters (bootstrap 99\%), one of which (subcluster $2 \beta^{824} \mathrm{II}$ ) contained artichoke isolates of VCG2Br ${ }^{824}$, VCG2B cotton isolate V357I from China, and HSI olive isolate V658I from Cyprus. The second subcluster $\left(2 \beta^{824} \mathrm{I}\right)$ consisted of cotton isolates from Israel and Greece.

$V$. dahliae isolates of VCG4B formed AFLP clusters $4 \beta \mathrm{I}$ and $4 \beta \mathrm{II}$, with $4 \beta \mathrm{I}$ containing only the three artichoke isolates placed in this VCG. All other VCG4B isolates in the study, regardless of geographic origin and host source, belong to $4 \beta I I$. Similarly, all VCG2A isolates grouped within the AFLP cluster $2 \alpha$ (Fig. 1). Isolates in $2 \alpha, 4 \beta \mathrm{I}$, and $4 \beta \mathrm{II}$ AFLP clusters were differentiated from those in clusters $2 \beta^{824}$ and 6 (bootstrap value of $96 \%$ ) (Fig. 1); and isolates in the $4 \beta I$ cluster were differentiated from those in clusters $4 \beta \mathrm{II}$ and $2 \alpha$ (bootstrap value of 99\%) (Fig. 1) Bootstrap value for the differentiation between isolates in cluster $2 \alpha$ and VCG4B isolates included in cluster $4 \beta \mathrm{II}$ was less than 65\%; however, AMOVA of AFLP data supported the two groups of isolates as significantly $(P<0.001)$ different populations (Table 2).

AFLP cluster $2 \alpha$, containing three subclusters (I through III), was the most heterogeneous cluster and included VCG2A isolates originating from six countries and three hosts. There was no association between those isolates' properties and their location in the clustering (Fig. 1). The differentiation of subcluster $2 \alpha$ II from subcluster $2 \alpha$ III was supported by bootstrap analysis (Fig. 1). The consistency of this distribution was supported by three of the four replicates used being clustered in this AFLP cluster $2 \alpha$.

\section{DISCUSSION}

Knowledge of the genetic diversity and structure in populations of $V$. dahliae gained through DNA and VCG analyses and their relationship with virulence phenotypes is a key factor for the efficient management of Verticillium wilt diseases through disease prediction and development of resistant cultivars. A previous study using PCR markers suggested that the predominant $V$. dahliae VCG2B from artichoke in eastern-central Spain is genetically heterogeneous, and that subgrouping of isolates associated with such heterogeneity correlates with virulence to artichoke and cotton cultivars (26). In this present study, with a large number of isolates representative of several VCGs and geographic origins 
and host sources, we aimed to examine further the genetic diversity within and among $V$. dahliae VCGs using AFLP analysis and PCR markers associated with cotton- and olive-D and -ND pathotypes.
This study demonstrates for the first time that $V$. dahliae isolates within a VCG subgroup are molecularly similar, to the extent that clustering of isolates by NJ analysis of their genetic distance calculated from AFLP data significantly correlated with

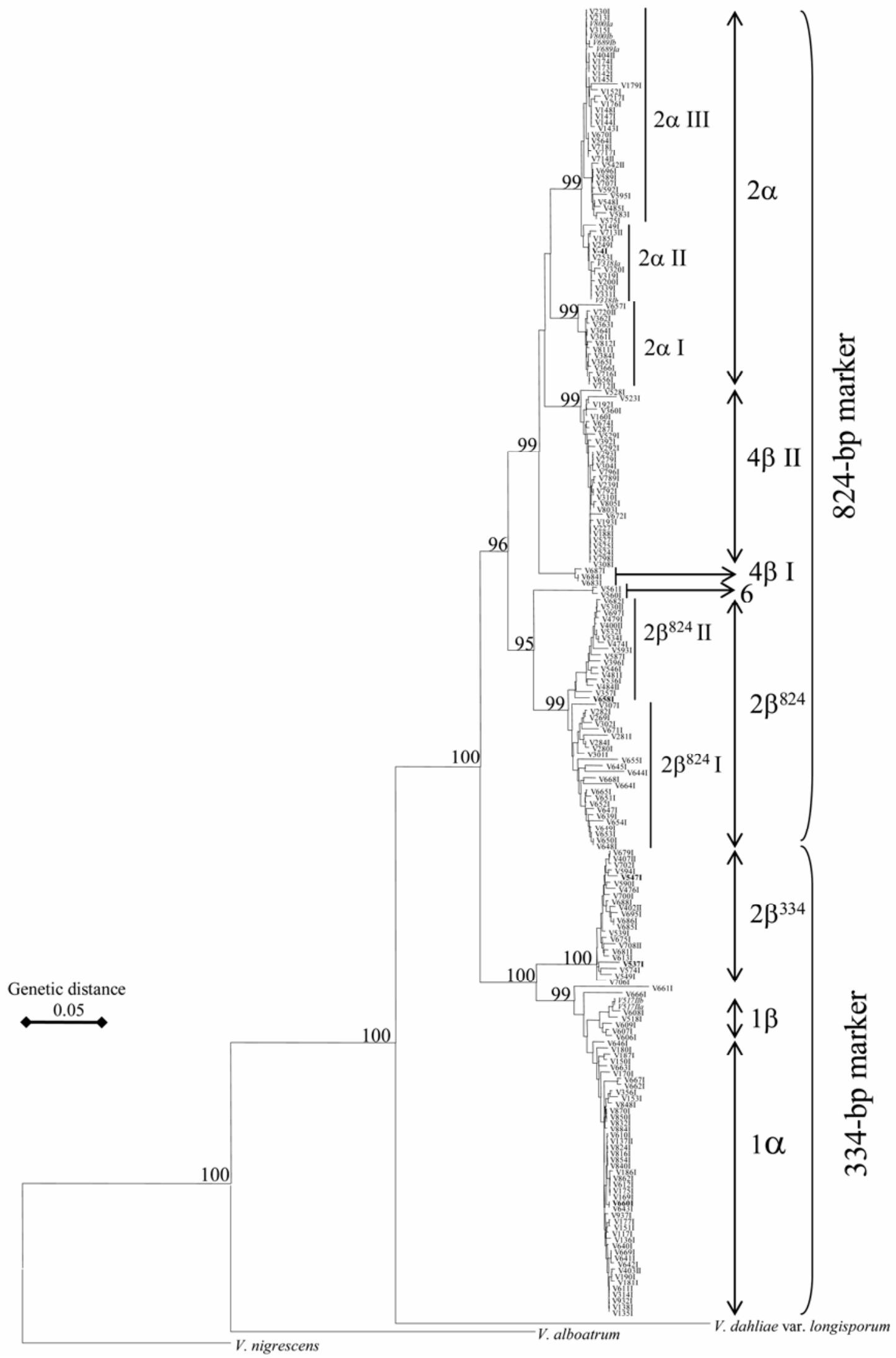

Fig. 1. Phenogram of genetic distance computed by the simple matching method (52) derived from neighbor-joining (49) analysis of 489 amplified fragment length polymorphic loci from 216 Verticillium isolates. Bootstrap values above 95 are shown (1,000 replicates). Replicates are denoted by $a$ and $b$ (isolates V800 I, V689 I, V318 I, and V517 II). Heterokaryon self-incompatible isolates are marked in bold. 
isolates' belonging to VCG subgroups. That correlation was independent of the method used for calculation of the genetic distance. Furthermore, results from the cluster analysis were consistent with those from AMOVA. Although Kosman and Leonard (34) indicated that the simple matching method may be more suitable than the Nei and Li method when using dominant markers to determine genetic similarity among closely related haploid microorganisms, our results suggest that the later method is suitable as well. Thus, we conclude that $V$. dahliae is a highly structured, clonal pathogen in which correlation between neutral genetic markers and vegetative compatibility can be used to infer relationship among VCGs. This is the first time that molecular variability and relationships within and among $V$. dahliae VCGs have been demonstrated using AFLPs based on a large sample of isolates representing diverse geographic origins and hosts. AFLPs had been used before to assess molecular variability in $V$. dahliae infecting cruciferous hosts $(16,22)$.

Few and contradictory data were available to adequately assess the molecular variability and relationships within and among V. dahliae VCGs $(8,9,13,19,25,33,35,42,60)$. For example, RAPD studies failed to demonstrate correlation between molecular grouping and VCG of isolates from a single host in one country $(13,35)$ or different countries $(33)$, as well as among isolates from different hosts in same regions $(8,9)$. The lack of clear molecular distinction between VCGs would suggest some gene flow between them, which is relevant in terms of potential for emergence of new virulence or pathogenicity in natural populations of the pathogen (4). Similarly, molecular variability among isolates within a VCG would indicate that those isolates do not have the same clonal lineage (8). The asexual reproduction in $V$. dahliaewhich results in the whole genome being transmitted as a unit from one generation to the next-together with the low number of VCGs generally found in natural populations of the fungus have been taken as an indication of a clonal structure in $V$. dahliae. However, the assumption that isolates within a VCG are clonally related should be made with caution (36). Vegetative compatibility is controlled by the action of a set of vegetative incompatibility (vic) or heterokaryon incompatibility (het) loci in ascomycetes, such that a stable heterokaryon is formed only when the two interacting strains carry the same alleles at all vic loci (36). If this genetic system operates in $V$. dahliae, a mutation at a single vic locus could result in closely related isolates becoming vegetatively incompatible; or, it might occur that distantly related isolates have by chance the same alleles at all vic loci and, thus, are vegetatively compatible. For example, in the asexually reproducing Fusarium oxysporum f. sp. melonis W.C. Snyder \& H.N. Hans., notable exceptions were found in the correlation between VCG and mtDNA or IGS haplotypes $(1,2)$, suggesting that, in some cases, vegetative compatibility may be coincidental rather than arising from common descent. In this present work, artichoke $V$. dahliae isolates of VCG2B were divided into two clusters $\left(2 \beta^{334}\right.$ and $\left.2 \beta^{824}\right)$ clearly differentiated at the molecular level. Moreover, none of the artichoke isolates showed molecular patterns intermediate to these two clusters, suggesting that very low genetic exchange, if any, may have taken place among isolates in different molecular groups even though they belong to the same VCG2B and originated from the same geographic area.

The accurate detection and identification of fluorescently labeled DNA fragments by capillary electrophoresis made it possible to demonstrate that isolates within a VCG are molecularly diverse, but isolates within a VCG subgroup are molecularly similar and can be clearly differentiated from those in other subgroups. Such

TABLE 2. Analysis of molecular variance of 489 amplified fragment length polymorphic (AFLP) fragments generated from 212 Verticillium isolates using four fluorescently labeled selective primer combinations

\begin{tabular}{|c|c|c|c|c|c|}
\hline Source of variation & $\mathrm{df}^{\mathrm{a}}$ & $\begin{array}{l}\text { Variance } \\
\text { components }\end{array}$ & $\begin{array}{l}\text { Percentage of } \\
\text { total variance }\end{array}$ & $\Phi$ Statistic & Probability $(P)^{\mathrm{b}}$ \\
\hline \multicolumn{6}{|l|}{ AFLP groups } \\
\hline Among groups & 7 & 25.21533 & 83.38 & $\Phi_{\mathrm{CT}}=0.83380$ & $P<0.001$ \\
\hline Within populations & 177 & 2.80025 & 9.26 & $\ldots$ & $\ldots$ \\
\hline \multicolumn{6}{|l|}{ Artichoke isolates } \\
\hline Among AFLP groups & 4 & 29.74210 & 90.88 & $\Phi_{\mathrm{CT}}=0.90877$ & $P<0.05$ \\
\hline Among populations within groups ${ }^{\mathrm{d}}$ & 2 & 0.30251 & 0.92 & $\Phi_{\mathrm{SC}}=0.10132$ & $P=0.090$ \\
\hline Among AFLP/VCG groups & 4 & 27.23723 & 88.05 & $\Phi_{\mathrm{CT}}=0.88053$ & $P<0.001$ \\
\hline Among populations within groups ${ }^{\mathrm{e}}$ & 11 & 0.83152 & 2.69 & $\Phi_{\mathrm{SC}}=0.22501$ & $P<0.001$ \\
\hline Within populations & 88 & 2.86400 & 9.26 & $\ldots$ & $\ldots$ \\
\hline \multicolumn{6}{|l|}{ Olive isolates } \\
\hline Among AFLP/VCG groups & 3 & 21.06068 & 75.36 & $\Phi_{\mathrm{CT}}=0.75363$ & $P<0.001$ \\
\hline Among populations within groups $\mathrm{e}$ & 6 & 4.14544 & 14.83 & $\Phi_{\mathrm{SC}}=0.60209$ & $P<0.001$ \\
\hline Within populations & 36 & 2.73969 & 9.80 & $\ldots$ & $\ldots$ \\
\hline \multicolumn{6}{|l|}{ VCG $2 B^{334} /$ AFLP group $2 \beta^{334}$} \\
\hline \multicolumn{6}{|l|}{ VCG $2 \mathrm{~B}^{334}$ and $2 \mathrm{Ba}$} \\
\hline Among populations & 1 & -0.08307 & -2.76 & $\Phi_{\mathrm{ST}}=-0.02756$ & $P=0.69676$ \\
\hline Within populations & 18 & 3.09768 & 102.76 & $\ldots$ & $\ldots$ \\
\hline \multicolumn{6}{|c|}{ VCG 4 B/AFLP group $4 \beta$ II and VCG 2 A /AFLP group $2 \alpha$} \\
\hline Among populations & 1 & 10.75511 & 67.31 & $\Phi_{\mathrm{ST}}=0.67306$ & $P<0.001$ \\
\hline Within populations & 84 & 5.22430 & 32.69 & W1 & $\ldots$ \\
\hline
\end{tabular}

${ }^{a}$ Degrees of freedom.

${ }^{\mathrm{b}}$ Probability of a larger value obtained by chance, determined by 3,000 randomizations of the data set. For populations, pairwise comparison significant $\Phi_{\mathrm{ST}} P$ values of $<0.05$.

${ }^{c}$ Populations within the groups according to host and geographic origins, except in AFLP cluster $2 \beta^{334}$ that were according to vegetative compatibility group (VCG) of isolates (2Br, 2Ba, and heterokaryon self-incompatible [HSI]).

d Populations among artichoke isolates were only present in AFLP cluster $2 \beta^{334}$ and according to VCG belonging (2Br, 2Ba, and HSI).

${ }^{\mathrm{e}}$ Populations within the groups according to geographic origin of isolates.

${ }^{\mathrm{f}}$ Cotton isolates V661I and V666I from Greece were not included in this analysis. When these isolates were included, the percentage of total variance among populations diminished to $40.64 \%$ with $P<0.001$. 
differentiation was possible regardless of host sources and geographic origins of isolates. However, the high resolution AFLPs also indicated molecular variability within some AFLP clusters or VCG subgroups associated with the geographic origin of isolates in some cases (e.g., cotton and olive isolates from Spain and cotton isolates from Greece and Turkey in AFLP cluster $1 \alpha /$ VCG1A) and with the host source (e.g., artichoke isolates from Spain in AFLP clusters $2 \beta^{334} / \mathrm{VCG} 2 \mathrm{~B}$, and $4 \beta \mathrm{II} / \mathrm{VCG} 4 \mathrm{~B}$ ) in others. Therefore, our results would support a clonal genetic structure in $V$. dahliae, the VCG subgrouping being correlated to inferred AFLP lineages.

Five isolates in the study from diverse host sources and geographic origins showed HSI. These isolates did not form a distinct AFLP cluster but were located in different AFLP or VCG clusters with no major molecular difference compared with heterokaryon self-compatible isolates in the same cluster. Such heterokaryon self-incompatibility could result from mutations in self-compatible isolates of the VCG associated with a particular AFLP cluster that led to a loss of the ability for heterokaryon self-compatibility. Interestingly, the HSI isolate V660I from cotton in Greece grouped close to VCG1A isolates from this country and all the isolates amplified the 334-bp PCR marker but not the D-associated 462-bp marker. Moreover, another cotton HSI isolate from Greece, isolate V661I, showed as vegetatively compatible with isolates of VCG1B and, therefore, was assigned to this VCG. Isolate V661I and VCG1B isolate V666I, also from Greece, produced different AFLP patterns. These patterns also differed from AFLP patterns produced by the rest of isolates of VCG1A and VCG1B.

An interesting result in this study was the separation by AFLP of the 824-bp PCR marker associated with the ND pathotype and the 334-bp DNA fragment formerly considered a marker of the D pathotype into two main clusters. Thus, the $\mathrm{VCG}_{2} \mathrm{Br}^{824}$ set of VCG2Br artichoke isolates from eastern-central Spain (26) shared the 824-bp amplicon with isolates of VCG2B from other hosts as well as of VCGs 2A, 4B, and 6. Conversely, artichoke isolates of VCG2Ba and VCG2Br ${ }^{334}$ shared the 334-bp PCR amplicon with isolates of AFLP clusters $1 \alpha$ and $1 \beta$ (i.e., AFLP cluster $2 \beta^{334}$ ). Interestingly, the artichoke isolates of $\mathrm{VCG} 2 \mathrm{Br}^{334}$ and $\mathrm{VCG} 2 \mathrm{Ba}$ subgroups within the $2 \beta^{334}$ AFLP cluster were differentiated by neither bootstrap analysis nor AMOVA but, as a group, were significantly less virulent to 'Acala SJ-2' cotton compared with isolates of $\mathrm{VCG} 2 \mathrm{Br}^{824}(26)$. However, such a difference in virulence between these two groups of isolates was small on artichoke and likely not biologically meaningful (26). The 334-bp amplicon previously was considered a marker for the $\mathrm{D}$ pathotype because the reverse primer espedef01 used for its amplification was designed from a 15-nucleotide indel present in $\mathrm{D} V$. dahliae from cotton and olive but lacking in ND isolates from these hosts (38). Now we have confirmed that this sequence also is present in V. dahliae isolates from artichoke (26) and have shown that it also occurs in isolates from other hosts that do not induce the D syndrome in cotton (R. M. Jiménez-Díaz, unpublished data), but are closely related to $V$. dahliae VCG1A.

The genetic diversity in the $V$. dahliae populations of this present study cannot be properly compared in terms of host sources and geographic origins using genotypic diversity indexes (e.g., Shannon-Wiener's or $H^{\prime}$ ) because the sampling strategy was not appropriate (24). However, we could measure the molecular diversity of isolates infecting a specific host (i.e., the richness of genotypes), but not the evenness of genotypes distribution within the populations (24). Molecular variability among $V$. dahliae isolates from artichoke was associated mainly with differences among the AFLP clusters, which explained $90.88 \%$ of the total molecular variation compared with $0.92 \%$ of it being due to differences among populations within the clusters. This low molecular variability within the specific AFLP groups likely was due to the narrow geographic origin of isolates. Artichoke isolates were spread across four main molecular groups, one of which, AFLP cluster $2 \beta^{334}$, was homogeneous in molecular terms but not in vegetative compatibility because it comprised the isolates of two VCGs, VCG2Ba and VCG2Br. Conversely, the three other molecular groups containing artichoke isolates correlated with VCG but were molecularly heterogeneous. For example, artichoke isolates were found in AFLP cluster $2 \beta^{824} \mathrm{II} / \mathrm{VCG} 2 \mathrm{~B}$ together with one cotton isolate from China and another from olive in Cyprus, but they clearly were differentiated from VCG2B isolates from cotton in Greece and Israel. Artichoke isolates also were in molecular cluster (4 $3 \mathrm{I})$ within VCG4B isolates of diverse geographic origins and host sources and in the $2 \alpha$ III subcluster of the heterogeneous AFLP $2 \alpha /$ VCG2A cluster. Therefore, with the exception of the two isolates from China and Cyprus, it appears that molecular similarity among artichoke isolates within each of VCG2B, VCG4B, and VCG2A from eastern-central Spain might result from a strong selection pressure exerted by the host in that geographic area. It is conceivable that emergence of a new strain of the pathogen with increased virulence to artichoke and without concomitant reduction in ecological adaptation likely would proliferate as a clone in the resident $V$. dahliae population. Consequently, isolates of this evolving clone should show a close genetic relatedness associated with the VCG of isolates $(8,9,23)$.

Cotton and olive isolates were spread across AFLP clusters $1 \alpha$, $2 \alpha, 2 \beta^{824}$, and $4 \beta$ II. Isolates in AFLP $4 \beta$ II were tightly clustered, indicating high molecular similarity. Because potato appears to be the preferred host for VCG4B isolates $(28,29,53)$, such a low molecular variability might be a consequence of potato being grown regularly in crop rotations practiced on cotton and olive fields $(26,32,33,56)$. Conversely, isolates of AFLP $2 \alpha /$ VCG2A cluster appeared to be molecularly heterogeneous, which would correspond with isolates of VCG2A having a broad host range $(7,21,32,33)$. A high variability among those latter isolates might have made the identification of significant molecular differences among cotton and olive isolates in the $2 \alpha$ AFLP cluster difficult. In contrast to these observations, there were significant molecular differences between cotton isolates in subcluster $2 \beta^{824} \mathrm{I}$ from China, Cyprus, and Spain compared with those in subcluster $2 \beta^{824} \mathrm{II}$ from Greece, Israel, and Turkey that could be attributable to geographic origin of isolates. Isolates of $V$. dahliae VCG2B occur worldwide on a relatively wide range of hosts, and prevalence of a particular molecular grouping among those isolates in a given area might reflect selection made by most frequent crops $(9,32,59)$.

Of particular interest was the molecular relationship between cotton and olive isolates in AFLP cluster $1 \alpha /$ VCG1A. Although molecular similarity grouped these isolates together, AMOVA identified significant molecular differences between VCG1A cotton isolates from Greece and Turkey compared with isolates with the D phenotype from cotton and olive in southern Spain. Lack of influence of host source on differences in molecular variability would be expected because cross virulence between cotton and olive isolates have been demonstrated by independent work in different geographic areas, and these two hosts are grown in close proximity at southern Spain $(47,51)$. In previous studies, RAPD analyses indicated high molecular similarity among D isolates from cotton at the southern part of the Guadalquivir Valley, southern Spain, were the pathotype was first reported $(5,33,44)$. The use of AFLPs and a wider collection of isolates in this study revealed molecular differences within these isolates. The molecular differences between D VCG1A isolates from Spain compared with VCG1A isolates from Greece and Turkey collectively would support the idea that new strains of VCG1A $V$. dahliae might develop in different geographic areas, or else that they have spread from a putatively common center of origin of VCG1A. The lack of the 462-bp sequence in VCG1A isolates from Greece and Turkey, which is a consistent marker of D V. dahliae $(38,40$; this work) regardless of host source and geographic origin, would support these two possibilities. 
In addition to our previous study of VCG diversity in $V$ dahliae infecting artichoke in Spain (26), diversity in $V$. dahliae VCG from cotton was investigated in Greece (21), Israel (32), and Spain (33); and V. dahliae from olive was studied in Israel (56) and Morocco (12). Limited VCG diversity was found in those latter studies, including VCG1A, VCG2A, VCG2B, and VCG4B among cotton isolates $(21,32,33)$ and VCG2A, VCG2B, and VCG4B among olive isolates $(12,56)$. A novelty of $V$. dahliae VCGs from this present study was the identification of VCG1B among cotton isolates from Greece, because V. dahliae VCG1B had been reported only from the United States and Canada up to now (7). Similarly, confirmation in this study of D isolates from olive in southern Spain as members of VCG1A is worth noting, because $\mathrm{D}$ isolates from olive and cotton show cross virulence $(47,51)$. In Spain, this pathotype has now spread from cotton crops at the southern part of the Guadalquivir Valley to olivegrowing areas in the northern valley $(5,38 ;$ R. M. Jiménez-Díaz, unpublished data).

In summary, the main conclusions of this work are (i) AFLP analysis clustered isolates according to their assignment to VCG subgroups, and most of the molecular variability among isolates could be associated to diversity among these subgroups; and (ii) isolates of a VCG subgroup were molecularly more similar to each other than to isolates from the same geographic origin or host source but with a different VCG. Some of the AFLP markers identified in this study may be of use to develop "universal" molecular markers for the characterization of isolates according to VCG and geographic origin (e.g., design of PCR-specific primer pairs). The development of these molecular tools would facilitate the characterization of $V$. dahliae populations in affected crops, the correct identification of inoculum sources, and the implementation of adequate disease control measures.

\section{ACKNOWLEDGMENTS}

This research was supported by grants AGL2000-1444 and AGL200300503 from Comisión Interministerial de Ciencia y Tecnología (CICYT) of Spain, and "Verticilosis del olivo" from Fundacion R. Areces. M. Collado-Romero is a recipient of a FPI fellowship from the Spanish Ministry of Education and Science (MEC) and J. Mercado-Blanco is a contract holder under the 'Ramón y Cajal' Programme of MEC. We thank J. Fahleson and C. Dixelius for helpful discussion on AFLP data analysis, M. G. Milgroom and N. Grünwald for helpful suggestions on earlier drafts of the manuscript, B. B. Landa del Castillo and J. A. Navas-Cortés for helpful comments on the manuscript, the senior editor and anonymous reviewers for suggestions and editorial improvement, J. Armengol and J. G. Jiménez for providing $V$. dahliae isolates from artichoke, and R. C. Rowe and T. Katan for providing reference strains of $V$. dahliae VCGs and Israeli nit testers, respectively.

\section{LITERATURE CITED}

1. Apple, D., and Gordon, T. R. 1995. Intraspecific variation within populations of Fusarium oxysporum based on RFLP analysis of the intergenic spacer region of the rDNA. Exp. Mycol. 19:120-128.

2. Apple, D., and Gordon, T. R. 1996. Relationships among pathogenic and nonpathogenic isolates of Fusarium oxysporum based on the partial sequence of the intergenic spacer region of the ribosomal DNA. Mol. Plant-Microbe Interact. 9:125-138.

3. Armengol, J., Berbegal, M., Giménez-Jaime, A., Romero, S., Beltrán, R., Vicent, A., Ortega, A., and García-Jiménez, J. 2005. Incidence of Verticillium wilt of artichoke in eastern Spain and role of inoculum sources on crop infection. Phytoparasitica 33:397-405.

4. Barbara, D. J., and Clewes, E. 2003. Plant pathogenic Verticillium species: How many of them are there. Mol. Plant Pathol. 4:297-305.

5. Bejarano-Alcázar, J. Blanco-López, M. A., Melero-Vara, J. M., and Jiménez-Díaz, R. M. 1996. Etiology, importance, and distribution of Verticillium wilt of cotton in Southern Spain. Plant Dis. 80:1233-1238.

6. Bell, A. A. 1992. Verticillium wilt. Pages 87-126 in: Cotton Diseases. J. H. Hillocks, ed. CAB International, Wallingford, UK.

7. Bell, A. A. 1994. Mechanisms of disease resistance in Gossypium species and variation in Verticillium dahliae. Pages 225-235 in: Proc. World
Cotton Res. Conf. 1. G. A. Constable and N. W. Forrester, eds. CSIRO, Melbourne, Australia.

8. Bhat, R. G., Smith, R. F., Koike, S. T., Wu, B. M., and Subbarao, K. V. 2003. Characterization of Verticillium dahliae isolates and wilt epidemics of pepper. Plant Dis. 87:789-797.

9. Bhat, R. G., and Subbarao, K. V. 1999. Host range specificity in Verticillium dahliae. Phytopathology 89:1218-1225.

10. Carder, J. H., Morton, A., Tabrett, A. M., and Barbara, D. J. 1994 Detection and differentiation by PCR of subspecific groups within two Verticillium species causing vascular wilts in herbaceous hosts. Pages 9197 in: Modern Assays for Plant Pathogenic Fungi. A. Schots, F. M. Dewey, and R. Oliver, eds. CAB International, Wallingford, UK.

11. Chen, W. 1994. Vegetative compatibility groups of Verticillium dahliae from ornamental woody plants. Phytopathology 84:214-219.

12. Cherrab, M., Bennani, A., Charest, P. M., and Serrhini, M. N. 2002. Pathogenicity and vegetative compatibility of Verticillium dahliae Kleb. isolates from olive in Morocco. J. Phytopathol. 150:703-709.

13. Cherrab, M., Serrhini, M. N., and Charest, P. M. 2000. Characterization of Moroccan isolates of Verticillium dahliae Kleb using RAPD markers. J. Phytopathol. 148:243-249.

14. Cirulli, M., Ciccarese, F., and Amenduni, M. 1994. Evaluation of Italian clones of artichoke for resistance to Verticillium dahliae. Plant Dis. 78:680-682.

15. Collins, A., Mercado-Blanco, J., Jiménez-Díaz, R. M., Olivares, C., Clewes, E., and Barbara, D. J. 2005. Correlation of molecular markers and biological properties in Verticillium dahliae and the possible origins of some isolates. Plant Pathol. 54:549-557.

16. Collins, A., Okoli, C. A. N., Morton, A., Parry, D., Edwards, S. G., and Barbara, D. J. 2003. Isolates of Verticillium dahliae pathogenic to crucifers are of at least three distinct molecular types. Phytopathology 93:364-376.

17. Correll, J. C., Klittich, C. J. R., and Leslie, J. F. 1987. Nitrate nonutilizing mutants of Fusarium oxysporum and their use in vegetative compatibility tests. Phytopathology 77:1640-1646.

18. Daayf, F., Nicole, M., and Geiger, J. P. 1995. Differentiation of Verticillium dahliae populations on the basis of vegetative compatibility and pathogenicity on cotton. Eur. J. Plant Pathol. 101:69-79.

19. Dobinson, K. F., Harrington, M. A., Omer, M., and Rowe, R. C. 2000. Molecular characterization of vegetative compatibility group $4 \mathrm{~A}$ and $4 \mathrm{~B}$ isolates of Verticillium dahliae associated with potato early dying. Plant Dis. 84:1241-1245.

20. Excoffier, L., Smouse, P. E., and Quattro, J. M. 1992. Analysis of molecular variance inferred from metric distances among DNA haplotypes: Applications to human mitochondrial DNA restriction data. Genetics 131:479-491.

21. Elena, K., and Paplomatas, E. J. 1998. Vegetative compatibility groups within Verticillium dahliae isolates from different hosts in Greece. Plant Pathol. 47:635-640.

22. Fahleson, J., Lagercrantz, U., Hu, Q., Steventon, L. A., and Dixelius, C. 2003. Estimation of genetic variation among Verticillium isolates using AFLP analysis. Eur. J. Plant Pathol. 109:361-371.

23. Fordyce, C., and Green, R. J. 1963. Alteration of pathogenicity of Verticillium albo-atrum var. menthae. Phytopathology 53:701-704.

24. Grünwald, N. J., Goodwin, S. B., Milgroom, M. G., and Fry, W. E. 2003. Analysis of genotypic diversity data for populations of microorganisms. Phytopathology 93:738-746.

25. Harris, D. C., and Yang, J. R. 1995. Characteristics of English isolates of Verticillium dahliae. Phytoparasitica 23:42.

26. Jiménez-Díaz, R. M., Mercado-Blanco, J., Olivares-García, C., ColladoRomero, M., Bejarano-Alcázar, J., Rodríguez-Jurado, D., Giménez-Jaime, A., García-Jiménez, J., and Armengol, J. 2006. Genetic and virulence diversity in Verticillium dahliae populations infecting artichoke in eastern-central Spain. Phytopathology 96:288-298.

27. Jiménez-Díaz, R. M., Tjamos, E. C., and Cirulli M. 1998. Verticillium wilt of major tree hosts: Olive. Pages 13-16 in: A Compendium of Verticillium Wilt in Trees Species. J. A. Hiemstra and D. C. Harris, eds. Ponsen \& Looijen, Wageningen, The Netherlands.

28. Joaquim, T. R., and Rowe, R. C. 1990. Reassessment of vegetative compatibility relationships among strains of Verticillium dahliae using nitratenonutlizing mutants. Phytopathology 80:1160-1166.

29. Joaquim, T. R., and Rowe, R. C. 1991. Vegetative compatibility and virulence strains of Verticillium dahliae from soil and potato plant. Phytopathology 81:552-558.

30. Katan, T. 2000. Vegetative compatibility in populations of Verticilliuman overview. Pages 69-86 in: Advances in Verticillium: Research and Disease Management. Proc. 7th Int. Verticillium Symp. E. C. Tjamos, R. C. Rowe, J. B Heale, and D. R. Fravel, eds. The American Phytopathological Society, St. Paul, MN.

31. Korolev, N., and Katan, T. 1997. Improved medium for selecting nitrate nonutilizing (nit) mutants of Verticillium dahliae. Phytopathology 87:1067-1070 
32. Korolev, N., Katan, J., and Katan, T. 2000. Vegetative compatibility groups of Verticillium dahliae in Israel: Their distribution and association with pathogenicity. Phytopathology 90:529-536.

33. Korolev, N., Pérez-Artés, E., Bejarano-Alcázar, J., Rodríguez-Jurado, D., Katan, J., Katan, T., and Jiménez-Díaz, R. M. 2001. Comparative study of genetic diversity and pathogenicity among populations of Verticillium dahliae from cotton in Spain and Israel. Eur. J. Plant Pathol. 107:443-456.

34. Kosman, E., and Leonard, K. J. 2005. Similarity coefficients from molecular markers in studies of genetic relationships between individuals for haploid, diploid, and polyploid species. Mol. Ecol. 14:415-424.

35. Lachqer, K., and Sedra, M. H. 2002. Characterisation of Verticillium dahliae Kleb. isolates from Olea europaea using RAPD markers. Phytopathol. Mediterr. 41:170-178.

36. Leslie, J. F. 1993. Fungal vegetative compatibility. Annu. Rev. Phytopathol. 31:127-150.

37. Levin, A. G., Lavee, S., and Tsror (Lahkim), L. 2003. Epidemiology of Verticillium dahliae on olive (cv. Picual) and its effect on yield under saline conditions. Plant Pathol. 52:212-218.

38. Mercado-Blanco, J., Rodríguez-Jurado, D., Parrilla-Araujo, S., and Jiménez-Díaz, R. M. 2003. Simultaneous detection of the defoliating and nondefoliating Verticillium dahliae pathotypes in infected olive plants by duplex, nested polymerase chain reaction. Plant Dis. 87:1487-1494.

39. Mercado-Blanco, J., Rodríguez-Jurado, D., Pérez-Artés, E., and Jiménez Díaz, R. M. 2001. Detection of the nondefoliating pathotype of Verticillium dahliae in infected olive plants by nested PCR. Plant Pathol. 50:1-12.

40. Mercado-Blanco, J., Rodríguez-Jurado, D., Pérez-Artés, E., and Jiménez Díaz, R. M. 2002. Detection of the defoliating pathotype of Verticillium dahliae in infected olive plants by nested PCR. Eur. J. Plant Pathol. 108:1-13.

41. Nei, M., and Li, W. H. 1979. Mathematical model for studying genetic variation in terms of restriction endonucleases. Proc. Natl. Acad. Sci. USA 76:5269-5273.

42. Okoli, C. A. N., Carder, J. H., and Barbara, D. J. 1993. Molecular variation and sub-specific groupings within Verticillium dahliae. Mycol. Res. 97:233-239.

43. Okoli, C. A. N., Carder, J. H., and Barbara, D. J. 1994. Restriction fragment length polymorphisms (RFLPs) and the relationships of some hostadapted isolates of Verticillium dahliae. Plant Pathol. 43:33-40.

44. Pérez-Artés, E., García-Pedrajas, M. D., Bejarano-Alcázar, J., and Jiménez-Díaz, R. M. 2000. Differentiation of cotton-defoliating and nondefoliating pathotypes of Verticillium dahliae by RAPD and specific PCR analyses. Eur. J. Plant Pathol. 106:507-517.

45. Pegg, G. F., and Brady, B. L. 2002. Verticillium Wilts. CAB International, Wallingford, UK.

46. Radišek, S., Jakše, J., Simončič, A., and Javornik, B. 2003. Characterization of Verticillium albo-atrum field isolates using pathogenicity data and AFLP analysis. Plant Dis. 87:633-638.
47. Rodríguez-Jurado, D., Blanco-López, M. A., Rapoport, H. F., and Jiménez-Díaz, R. M. 1993. Present status of Verticillium wilt of olive in Andalucia (southern Spain). Bull. OEPP/EPPO Bull. 23:513-516.

48. Rowe, R. C. 1995. Recent progress in understanding relationships between Verticillium species and subspecific groups. Phytoparasitica 23:31-38.

49. Saitou, N., and Nei, M. 1987. The neighbour-joining method: A new method for reconstructing phylogenetic trees. Mol. Biol. Evol. 4:406-425.

50. Schnathorst, W. C., and Mathre, D. E. 1966. Host range and differentiation of a severe form of Verticillium albo-atrum in cotton. Phytopathology 56:1155-1161.

51. Schnathorst, W. C., and Sibbet, G. S. 1971. The relation of strains of Verticillium albo-atrum to severity of Verticillium wilt in Gossypium hirsutum and Olea europaea in California. Plant Dis. Rep. 9:780-782.

52. Sneath, P. A., and Sokal, R. R. 1973. Numerical Taxonomy. W. H. Freeman and Co., San Francisco.

53. Strausbaugh, C. A., Schroth, N. M., Weinhold, A. R., and Hancock, J. G. 1992. Assessment of vegetative compatibility of Verticillium dahliae tester strains and isolates from California potatoes. Phytopathology 82:6168.

54. Talboys, P. W. 1960. A culture medium aiding the identification of Verticillium albo-atrum and V. dahliae. Plant Pathol. 9:58-59.

55. Truett, G. E., Heeger, P., Mynatt, R. L., Truett, A. A., Walker, J. A., and Warman, M. L. 2000. Preparation of PCR-quality mouse genomic DNA with hot sodium hydroxide and Tris (HotSHOT). BioTechniques 29:5254.

56. Tsror, L. (Lahkim), Levin, A., Hazanowsky, M., Erlich, O., Sharon, M., Yogev, U., and Gamliel, A. 2000. Verticillium wilt on olives. Page 268 in: Abstracts of Presentations. 21st Congress of the Israeli Phytopathological Society, Bet Dagan, Israel.

57. Van de Peer, Y., and De Wachter, R. 1994. TREECON for Windows: A software package for the construction and drawing of evolutionary trees for the Microsoft Windows environment. Comput. Appl. Biosci. 10:569570.

58. Vos, P., Hogers, R., Bleeker, M., Reijans, M., Vandelee, T., Hornes, M., Frijters, A., Pot, J., Peleman, J., Kuiper, M., and Zabeau, M. 1995. AFLP: A new technique for DNA fingerprinting. Nucleic Acids Res. 23:44074414.

59. Zeise, K., and von Tiedemann, A. 2002. Host specialization among vegetative compatibility groups of Verticillium dahliae in relation to Verticillium longisporum. J. Phytopathol. 150:112-119.

60. Zeise, K., and von Tiedemann, A. 2002. Application of RAPD-PCR for virulence type analysis within Verticillium dahliae and V. longisporum. J. Phytopathol. 150:557-563.

61. Zhengjun, X., Achar, P. N., and Benkang, G. 1998. Vegetative compatibility grouping of Verticillium dahliae from cotton in mainland China. Eur. J. Plant Pathol. 104:871-876. 